\title{
Reação de genótipos de feijão-fava a Sclerotium rolfsii
}

\author{
Jeferson A Silva' ${ }^{1}$; Marcelo G Oliveira ${ }^{1}$; Leonardo T Souza' ${ }^{1}$ Iraildes P Assunção² ${ }^{2}$ Gaus A Lima²; Sami J \\ Michereff $^{1}$
}

${ }^{1}$ UFRPE, Depto. Agronomia, R. Dom Manoel de Medeiros s/n, Dois Irmãos, 52171-900 Recife-PE; jefersonaraujos.bio@hotmail.com; marcelopb1bio@gmail.com; leoagronomia@yahoo.com.br; smichereff@gmail.com; ${ }^{2}$ UFAL-CCA, Av. Lourival Melo Mota s/n, 57072900 Maceió-AL; i_assuncao@hotmail.com; gausandrade@yahoo.com.br

\section{RESUMO}

A podridão do colo, causada por Sclerotium rolfsii, é uma importante doença do feijão-fava (Phaseolus lunatus) no Nordeste brasileiro. O objetivo deste trabalho foi avaliar a reação de genótipos de feijão-fava a $S$. rolfsii, visando selecionar materiais com potencial de utilização no manejo da podridão do colo. Na primeira etapa, 50 genótipos de feijão-fava foram avaliados em relação a um isolado de S. rolfsii. Plantas com 10 dias de idade foram inoculadas pelo método de ferimento do colo e deposição do escleródio do patógeno. A incidência da doença foi avaliada 10 dias após a inoculação. A maioria dos genótipos $(60 \%)$ se comportou como altamente suscetível ao patógeno, enquanto $36 \%$ foram classificadas como suscetíveis. Somente dois genótipos (F-2 e F-25) se comportaram como altamente resistentes, correspondendo a 4\% do total. A estabilidade da resistência destes dois genótipos foi avaliada em relação a 11 isolados de $S$. rolfsii, sendo que ambos apresentaram nível de resistência satisfatório, constituindo fontes promissoras de resistência à podridão do colo.

Palavras-chave: Phaseolus lunatus, podridão do colo, resistência genética.

\begin{abstract}
Reaction of faba bean genotypes to Sclerotium rolfsii

The collar rot caused by Sclerotium rolfsii is an important disease in faba bean (Phaseolus lunatus) at the Northeastern Brazil. The objective of this work was to evaluate the reaction of faba bean genotypes to $S$. rolfsii in order to select materials with potential use in the collar rot management. In the first step, 50 faba bean genotypes were evaluated in relation to an isolate of $S$. rolfsii. Ten-day old plants were inoculated by the collar injury method and deposition of sclerotia of the pathogen. Disease incidence was assessed 10 days after inoculation. Most genotypes (60\%) behaved as highly susceptible to the pathogen, while $36 \%$ were classified as susceptible. Only two genotypes (F-2 and F-25) behaved as highly resistant, representing $4 \%$ of the total. The stability of resistance of these two genotypes was evaluated against 11 isolates of $S$. rolfsii, both of them showing satisfactory level of resistance, constituting promising sources of resistance to collar rot.
\end{abstract}

Keywords: Phaseolus lunatus, collar rot, genetic resistance.

(Recebido para publicação em 22 de fevereiro de 2013; aceito em 6 de fevereiro de 2014) (Received on February 22, 2013; accepted on February 6, 2014)

$\mathrm{O}$ feijão-fava (Phaseolus lunatus), também conhecido como feijão-lima e fava, é uma importante fonte de proteína na alimentação humana, sendo consumido como grãos verdes ou secos ou como vagens verdes (Vieira, 1992). A região Nordeste é responsável por mais de $95 \%$ da produção brasileira de feijão-fava, atingindo em 2010 uma área plantada de 28.628 ha e produção de 6.667 toneladas (IBGE, 2012). Nessa região, o feijão-fava constitui importante alternativa de renda e fonte de alimento para a população (Guimarães et al., 2007), sendo cultivado principalmente em consórcio com milho, em pequenas propriedades (Silva et al., 2010).

Apesar da adaptação às condições edafoclimáticas do Nordeste brasileiro, o feijão-fava tem sua produtividade reduzida devido à ocorrência de doenças (Assunção et al., 2011). Dentre estas, a podridão do colo, causada por Sclerotium rolfsii, pode provocar per- das no rendimento e na qualidade dos grãos (IPGRI, 2001). Os sintomas da doença assemelham-se aos verificados em outras fabáceas, aparecendo inicialmente no colo da planta, ao nível do solo, como manchas escuras, encharcadas, estendendo-se pela raiz principal e produzindo uma podridão cortical, frequentemente recoberta por um micélio branco, no qual se desenvolvem numerosos escleródios, de tamanho uniforme, que são brancos quando imaturos, tornando-se marrom-escuros na maturidade. Na parte aérea, as plantas apresentam amarelecimento e desfolhação dos ramos superiores e uma murcha repentina que conduz à seca total. Os estádios fenológicos de emergência, folhas primárias abertas e primeira folha trifoliada aberta são os mais afetados pela doença (Cardoso, 1994).

O controle podridão do colo em feijão-fava é muito difícil (Punja, 1985). Como no caso de outras doenças cau- sadas por fitopatógenos habitantes do solo, a diagnose precoce é difícil, uma vez que, frequentemente, os sintomas na parte aérea podem ser confundidos com deficiências nutricionais, déficit hídrico ou fitotoxidez, dentre outros. O controle químico não é usualmente econômico e tecnicamente viável, além de apresentar uma série de restrições do ponto de vista ambiental. O controle biológico tem se mostrado limitado na maioria das situações, pois são poucos os antagonistas que conseguem se estabelecer num ambiente tão competitivo, além das dificuldades técnicas para a produção massal, formulação e aplicação dos agentes de biocontrole. Medidas culturais como a rotação de culturas em razão das eficientes estratégias de sobrevivência desses patógenos, exigem longos períodos de ausência da cultura principal, o que reduz substancialmente sua aplicabilidade (Lima et al., 2005).

O plantio de cultivares resistentes é, 
sem dúvida, o método ideal de controle de doenças em plantas, pois apresenta vantagens como baixo custo, fácil uso, alta eficácia e ecologicamente desejável. A resistência genética é característica herdável e, na natureza, o nível de resistência de plantas a patógenos varia de plantas altamente suscetíveis a plantas altamente resistentes ou até mesmo imunes (Mizubuti \& Maffia, 2007).

Devido à dificuldade no controle, a seleção de genótipos de feijão-fava com resistência genética a $S$. rolfsii pode ser a melhor alternativa de manejo, porém ainda não foi explorada. Os testes iniciais para este fim devem ser executados sob condições menos variáveis possíveis. $\mathrm{O}$ presente trabalho teve como objetivo avaliar a reação de genótipos de feijão-fava a $S$. rolfsii, visando selecionar materiais com potencial de utilização no manejo da podridão do colo.

\section{MATERIAL E MÉTODOS}

A avaliação da resistência de genótipos de feijão-fava a $S$. rolfsii foi realizada em dois ensaios. Inicialmente foi efetuada a seleção de genótipos promissores e depois analisada a estabilidade da resistência desses genótipos em relação a diferentes isolados do patógeno. As duas etapas foram realizadas em casa de vegetação, com temperatura do ar variando entre 23 e $32^{\circ} \mathrm{C}$ e umidade relativa do ar entre 61 e $87 \%$, na Área de Fitossanidade do Depto. de Agronomia da Universidade Federal Rural de Pernambuco, em Recife-PE.

Na seleção de genótipos promissores, uma coleção de 50 genótipos de feijão-fava, oriundos de vários estados do Nordeste brasileiro e preservados nos Bancos de Germoplasmas da Universidade Federal de Alagoas (35 acessos) e da Universidade Federal Rural de Pernambuco (15 acessos), foi avaliada em relação a um isolado de $S$. rolfsii (CMM-3027), obtido de planta de feijão-caupi com sintoma de podridão do colo coletada em São João-PE. O inóculo de $S$. rolfsii foi preparado em placas de Petri contendo o meio de cultura batata-dextrose-ágar (BDA) incubado à temperatura de $28^{\circ} \mathrm{C}$ e fotoperíodo de $12 \mathrm{~h}$, durante 45 dias (Punja,
1985). Posteriormente, os escleródios maduros foram retirados da superfície do meio de cultura e transferidos para placas de Petri esterilizadas para utilização na inoculação. Uma amostra de 100 escleródios foi transferida para meio ágar-água para avaliação da viabilidade, sendo constatada a germinação de $98 \%$ dos escleródios.

As sementes de feijão-fava, antes do plantio, foram desinfestadas em solução de hipoclorito de sódio ( $\mathrm{NaOCl} 1 \%)$ por dois minutos e colocadas para secar ao ar durante 45 minutos. Em seguida, foram semeadas em vasos plásticos (3 $\mathrm{kg}$ de capacidade), contendo solo franco arenoso $(\mathrm{pH}=6,4 ; \mathrm{N}=1.030$ ppm; $\mathrm{P}=3 \mathrm{mg} / \mathrm{dm}^{3} ; \mathrm{K}=0,14 \mathrm{cmol} / \mathrm{dm}^{3}$; $\left.\mathrm{Ca}+\mathrm{Mg}=0,80 \mathrm{cmol}_{\mathrm{c}} / \mathrm{dm}^{3}\right)$. Nove dias após o plantio foi realizado o desbaste, permanecendo cinco plantas por vaso, as quais foram inoculadas com 10 dias de idade, a partir da semeadura, o que correspondeu ao estádio de primeira folha trifoliada aberta. A inoculação foi realizada ferindo-se levemente o colo de cada planta em três locais com agulha flambada, e depositando-se um escleródio em cada ferimento, totalizando três escleródios por planta. As plantas foram mantidas em câmara úmida por $48 \mathrm{~h}$ (Dantas et al., 2002). O delineamento experimental foi inteiramente casualizado, com quatro repetições, sendo cada repetição constituída por um vaso com cinco plantas. A avaliação da doença foi realizada aos 10 dias após a inoculação, pela contagem do número de plantas com podridão do colo e cálculo da incidência da doença, representada pela porcentagem de plantas com sintomas em relação ao total de plantas por vaso. Os dados de incidência foram submetidos à análise de variância (ANOVA) e as médias dos genótipos comparadas pelo teste de Scott-Knott $(p=0,05)$.

Baseado no ensaio anterior foram selecionados três genótipos de feijão-fava para análise da estabilidade da resistência, sendo dois genótipos que apresentaram menor incidência da doença (F-2 e F-25) e o genótipo que apresentou maior incidência da doença (F-8). Esses genótipos foram avaliados em relação a 11 isolados de $S$. rolfsii obtidos de plantas de feijão-caupi com sintomas de podridão do colo coletadas nos mu- nicípios de São João-PE (CMM-3027, CMM-3030, CMM-3094, CMM-3095 e CMM-3096), Lajedo-PE (CMM-3049 e CMM-3091), Garanhuns-PE (CMM3085 e CMM-3088), Jupi-PE (CMM1169) e Alhandra-PB (CMM-3051). O solo e os procedimentos de produção de inóculo, inoculação do patógeno, plantio de feijão-fava e avaliação da doença foram os mesmos adotados na seleção de genótipos promissores. $\mathrm{O}$ delineamento experimental foi inteiramente casualizado, em arranjo fatorial $3 \times 11$, com três repetições, sendo cada repetição constituída por um vaso com quatro plantas. Os dados de incidência foram submetidos à análise de variância (ANOVA) e as médias comparadas pelo teste LSD de Fisher $(p=0,05)$.

\section{RESULTADOS E DISCUSSÃO}

$\mathrm{Na}$ maioria dos genótipos, os primeiros sintomas da doença apareceram aos dois dias após a inoculação, observando-se lesões deprimidas na região do colo onde o escleródio foi depositado, recobertas por um micélio branco. Com o passar do tempo ocorreu a produção de mais escleródios, no colo da planta e no solo, e posteriormente, murcha e seca da planta.

Dentre os 50 genótipos de feijão-fava avaliados quanto à resistência a $S$. rolfsii, somente os genótipos F-2 e F-25 comportaram-se como altamente resistentes, correspondendo a $4 \%$ do total. Para o genótipo F-2 foi registrada uma incidência de $25 \%$, enquanto que para F-25 a incidência foi de 10\%. A maioria dos genótipos, ou seja 30, o que correspondeu a $60 \%$ do total avaliado, se comportou como altamente suscetível. Os outros 18 genótipos, ou $36 \%$ do total, se comportaram como suscetíveis. Esses resultados evidenciam a dificuldade na obtenção de fontes com elevados níveis de resistência a $S$. rolfsii em genótipos de feijão-fava, provavelmente devido ao processo de patogênese exercido, resultante da elevada produção de enzimas hidrolíticas (Pratt \& Rowe, 2002; Agrios, 2005; Vidhyasekaran, 2008).

De modo geral, os problemas fitossanitários da cultura do feijão-fava têm recebido pequena atenção. Contudo, nos 
Tabela 1. Reação de três genótipos de feijão-fava (F-2, F-8 e F-25) a isolados de Sclerotium rolfsii sob condições de casa de vegetação [reaction of three faba bean genotypes (F-2, F-8 and F-25) to isolates of Sclerotium rolfsii, in protected environment]. Recife, UFRPE, 2010.

\begin{tabular}{llrl}
\hline \multirow{2}{*}{$\begin{array}{l}\text { Isolado de Sclerotium } \\
\text { rolfsii }\end{array}$} & \multicolumn{3}{c}{ Genótipo/incidência (\%) } \\
\cline { 2 - 4 } & $\mathbf{F - 2}$ & $\mathbf{F - 8}$ & $\mathbf{F}-25$ \\
\hline CMM-1169 & $26,7 \mathrm{bcB}^{2}$ & $100,0 \mathrm{aA}$ & $33,3 \mathrm{bcB}$ \\
CMM-3027 & $20,0 \mathrm{cB}$ & $100,0 \mathrm{aA}$ & $10,0 \mathrm{~dB}$ \\
CMM-3030 & $33,3 \mathrm{bcB}$ & $93,3 \mathrm{aA}$ & $26,7 \mathrm{cdB}$ \\
CMM-3049 & $40,0 \mathrm{bcC}$ & $100,0 \mathrm{aA}$ & $73,3 \mathrm{aB}$ \\
CMM-3051 & $26,7 \mathrm{bcB}$ & $100,0 \mathrm{aA}$ & $26,7 \mathrm{cdB}$ \\
CMM-3085 & $53,3 \mathrm{abAB}$ & $80,0 \mathrm{bA}$ & $40,0 \mathrm{bcB}$ \\
CMM-3088 & $73,3 \mathrm{aB}$ & $100,0 \mathrm{cA}$ & $26,7 \mathrm{cdC}$ \\
CMM-3091 & $46,7 \mathrm{abcB}$ & $93,3 \mathrm{aA}$ & $53,3 \mathrm{abAB}$ \\
CMM-3094 & $53,3 \mathrm{abB}$ & $100,0 \mathrm{aA}$ & $26,7 \mathrm{cdB}$ \\
CMM-3095 & $33,3 \mathrm{bcB}$ & $100,0 \mathrm{aA}$ & $40,0 \mathrm{bcB}$ \\
CMM-3096 & $26,7 \mathrm{bcB}$ & $66,7 \mathrm{cA}$ & $26,7 \mathrm{cdB}$ \\
\hline
\end{tabular}

${ }^{1}$ Média de três repetições da incidência da doença, considerando a porcentagem de plantas com sintomas em relação ao total de plantas inoculadas por vaso; ${ }^{2}$ Médias seguidas pela mesma letra minúscula na coluna e maiúscula na linha não diferem significativamente entre si pelo teste LSD de Fisher $(p=0,05)$ [ ${ }^{1}$ average of three replications of disease incidence, considering the percentage of plants with symptoms in relation to the total of inoculated plants per vase; ${ }^{2}$ means followed by the same lowercase letter in column and uppercase letter in line do not differ statisticaly by the test LSD of Fisher $(p=0.05)]$.

últimos anos a cultura tem se valorizado e algumas pesquisas sobre esse aspecto têm surgido. Em 2009, a reação de 70 genótipos de feijão-fava foi avaliada em relação ao mosaico e à antracnose, causados respectivamente pelo Bean golden mosaic virus e por Colletotrichum truncatum. Dez genótipos foram considerados resistentes a ambas as doenças e dentre eles dois se destacaram também pela alta produtividade: F-20 e F-45 (Nordeste Rural, 2010). No entanto, no presente trabalho, esses dois genótipos se comportaram como suscetíveis à podridão do colo. Em 2011, foi avaliada a reação de 72 genótipos de feijão-fava à Rhizoctonia solani e quatro genótipos (F-42, F-49, F-53 e F-58) demonstraram reação de alta resistência ao patógeno (Assunção et al., 2011). No presente estudo, somente os genótipos F-42 e F-49 foram avaliados e comportaram-se como suscetíveis a $S$. rolfsii.

As dificuldades para encontrar fontes de resistência às doenças ocasionadas por $S$. rolfsii são relatadas em várias culturas (Bedendo, 2011), no entanto, em algumas situações, genótipos moderadamente resistentes ou tolerantes têm sido identificados. Foi o caso da pesquisa conduzida por Dantas et al. (2002), na qual foram avaliados 30 genótipos de feijão-comum (Phaseolus vulgaris), sendo cinco desses genótipos apontados como promissores. As bases anatômicas, morfológicas ou fisiológicas para esses comportamentos são em muitos casos desconhecidas, contudo podem envolver tecidos bastante lignificados ou suberizados, nos quais uma camada impermeável de felogênio é formada por tecidos contendo proteínas inibidoras de endopoligalacturonases (Punja, 1985). Outro exemplo de resistência genética a $S$. rolfsii foi relatado para a cultura da alfafa (Medicago sativa), sendo nesse caso a resistência caracterizada como poligênica (Pratt \& Rowe, 2002).

Os dois genótipos altamente resistentes (F-2 e F-25) e um genótipo altamente suscetível (F-8) foram avaliados quanto à estabilidade da reação da doença em relação a 11 isolados de $S$. rolfsii. Todos os isolados de $S$. rolfsii foram capazes de causar doença em feijão-fava, embora nenhum tenha sido obtido originalmente do patossistema estudado. Essa flexibilidade de $S$. rolfsii tem sido evidenciada em outros patossistemas, caracterizada pela capacidade de causar doença em diferentes hospedeiros, independente do hospedeiro de origem (Punja, 1985;
Flores-Moctezuma et al., 2006).

$\mathrm{Na}$ avaliação da estabilidade das reações, foram constatadas diferenças nos níveis de incidência da podridão do colo entre os genótipos, bem como entre os isolados separadamente. No entanto, a interação entre genótipos e isolados foi significativa $(\mathrm{p} \leq 0,05)$, indicando que os genótipos podem variar de reação conforme o isolado, bem como os isolados podem causar diferentes níveis de doença conforme o genótipo (Tabela 1). Interações diferencias entre isolados de $S$. rolfsii e genótipos de feijão-comum também foram relatadas por Dantas et al. (2002) e reforçam a necessidade da utilização de isolados de diferentes procedências nas avaliações visando resistência a esse patógeno.

As reações apresentadas pelos genótipos promissores de feijão-fava (F-2 e F-25) variaram conforme o isolado de $S$. rolfsii (Tabela 1), indicando a ocorrência de variabilidade na virulência entre os isolados do patógeno (Punja, 1985; Adandonon et al., 2005). O genótipo F-8, que se comportou como altamente suscetível no primeiro ensaio apresentou reação de alta suscetibilidade à maioria dos isolados (Tabela 1).

O bom nível de resistência observado nos genótipos F-2 e F-25 para a maioria dos isolados demonstra o potencial do uso desses genótipos como estratégia de manejo da podridão do colo da cultura do feijão-fava. Estudos para determinar a estabilidade dessa resistência em diferentes densidades de inóculo do patógeno e diferentes tipos de solo devem ser implementados, assim como pesquisas para determinar as causas dessa resistência e seu controle genético.

A literatura não registra trabalhos conduzidos com objetivo de avaliar a reação do germoplasma do feijão-fava a $S$. rolfsii, portanto essa foi a primeira pesquisa no assunto. Pelo fato do feijão-fava ser cultivado por pequenos produtores, a resistência genética torna-se a principal estratégia de manejo, principalmente para um fitopatógeno habitante de solo que produz estruturas de sobrevivência e apresenta ampla gama de hospedeiras (Falcão et al., 2005; Bedendo, 2011).

Os resultados desse trabalho demonstram a possibilidade do uso dos 
genótipos F-2 e F-25 em áreas infestadas com $S$. rolfsii. Esses materiais também podem funcionar como fontes de resistência em cruzamentos realizados em futuros programas de melhoramento genético para transferência deste caráter para outros genótipos de feijão-fava, que apresentem características agronômicas satisfatórias.

\section{AGRADECIMENTOS}

Aos bancos de germoplasma de feijão-fava da UFRPE e da UFAL pelo fornecimento das sementes e ao Conselho Nacional de Desenvolvimento Científico e Tecnológico (CNPq) pelo apoio financeiro.

\section{REFERÊNCIAS}

ADANDONON A; AVELING TAS; VAN DER MERWE NA; SANDERS G. 2005. Genetic variation among Sclerotium isolates from Benin and South Africa, determined using mycelial compatibility and ITS rDNA sequence data. Australasian Plant Pathology 34: $19-25$.

AGRIOS GN. 2005. Plant pathology. 5. ed. San Diego: Academic Press. 952p.

ASSUNÇÃOIP; NASCIMENTO LD; FERREIRA MF; OLIVEIRA FJ; MICHEREFF SJ; LIMA
GSA. 2011. Reaction of faba bean genotypes to Rhizoctonia solani and resistance stability. Horticultura Brasileira 29: 492-497.

BEDENDO IP. 2011. Podridões de raiz e colo. In: AMORIM L; REZENDE JAM; BERGAMIM FILHO A. Manual de fitopatologia: principios e conceitos. 4p. São Paulo: Ceres, p.443-449.

CARDOSO JE. 1994. Podridão do colo. In: SARTORATO A; RAVA CA (eds). Principais doenças do feijoeiro comum e seu controle. Brasília: EMBRAPA-SPI. p.164-173.

DANTAS SAF; OLIVEIRA SMA; COELHO RSB; SILVA RLX. 2002. Identificação de fontes de resistência em feijoeiro a Sclerotium rolfsii. Fitopatologia Brasileira 27: 528-531.

FALCÃO JV; ORILI FP; ÁVILA ZR; MELLO SCM. 2005. Estabelecimento de metodologia para contaminação de solo com propágulos dos fungos Sclerotinia sclerotiorum e Sclerotium rolfsii, e expressão de doença em soja. Brasília: Embrapa Recursos Genéticos e Biotecnologia. 9p.

FLORES-MOCTEZUMA HE; MONTESBELMONT R; NAVA-JUAREZ R. 2006. Pathogenic diversity of Sclerotium rolfsii isolates from Mexico and its potential control through solarization and organic amendments. Crop Protection 25: 195-201.

GUIMARÃES WNR; MARTINS LSS; SILVA EF; FERRAZ GMG; OLIVEIRA FJ. 2007. Caracterização morfológica e molecular de acessos de feijão-fava (Phaseolus lunatus L.). Revista Brasileira de Engenharia Agrícola e Ambiental 11: 37-45.

IBGE. 2012. SIDRA - sistema IBGE de recuperação automática. Rio de Janeiro: Instituto Brasileiro de Geografia e Estatística. Disponível em <http://www.sidra.ibge.gov. br>. Acesso em: 25 ago. 2012.

IPGRI. 2001. Descritores para Phaseolus lunatus L. (Feijão espadinho). Rome: International Plant Genetic Resources Institute. 51p.

LIMA GSA; ASSUNÇÃO IP; VALLE LAC. 2005. Controle genético de doenças radiculares. In: MICHEREFF SJ; ANDRADE DEGT; MENEZES M (eds). Ecologia e manejo de patógenos radiculares em solos tropicais. Recife: Imprensa da UFRPE. p. 247-278.

MIZUBUTI ESG; MAFFIA LA. 2007. Introdução à Fitopatologia. Viçosa: Editora da UFV. 190p.

NORDESTE RURAL. 2010, 16 de maio. Descoberta fava resistente a doenças. Disponível em http://www.tvverdesmares.com. br/nordesterural/descoberta-favaresistentea-doencas/

PRATT RG; ROWE DE. 2002. Enhanced resistance to Sclerotium rolfsii in populations of alfalfa selected for quantitative resistance to Sclerotinia trifoliorum. Phytopathology 92: 204-209.

PUNJA ZK. 1985. The biology, ecology and control of Sclerotium rolfsii. Annual Review of Phytopathology 23: 97-127.

SILVA KJD; LOPES ACA; GOMES RLF; SOUSA FM; ROCHA MM. 2010. Recursos genéticos. In: LOPES ACA; GOMES RLF; ARAÚJO ASF (eds). A cultura do feijão-fava no Meio-Norte do Brasil. Teresina: Editora da UFPI. 272p.

VIDHYASEKARAN P. 2008. Fungal pathogenesis in plants and crops molecular biology and host defense mechanisms. 2. ed. Boca Raton: CRC Press. 509p.

VIEIRA RF. 1992. A cultura do feijão-fava. Informe Agropecuário 16: 30-37. 